\title{
Nanoscale Cerium Oxide: Synthesis, Biocatalytic Mechanism, and Applications
}

\author{
Guangchun Song ${ }^{1}$, Nan Cheng ${ }^{1, *} \mathbb{1}$, Junjie Zhang ${ }^{1}$, Huixian Huang ${ }^{1}$, Yanfang Yuan ${ }^{2}$, Xiaoyun He ${ }^{1}$, \\ Yunbo Luo ${ }^{1,3}$ and Kunlun Huang ${ }^{1,3, *}$ \\ 1 Beijing Laboratory for Food Quality and Safety, College of Food Science and Nutritional Engineering, \\ China Agricultural University, Beijing 100083, China; sgc@cau.edu.cn (G.S.); sy20203061089@cau.edu.cn (J.Z.); \\ sy20203061108@cau.edu.cn (H.H.); raininghe@163.com (X.H.); lyb@cau.edu.cn (Y.L.) \\ 2 Research and Development Division, National Medical Products Administration Institute of Executive \\ Development (NMPAIED), Beijing 100073, China; yyf@nmpaied.org.cn \\ 3 Key Laboratory of Safety Assessment of Genetically Modified Organism (Food Safety), Ministry of Agriculture, \\ Beijing 100083, China \\ * Correspondence: chengnanFSNE@cau.edu.cn (N.C.); hk1009@163.com (K.H.)
}

check for

updates

Citation: Song, G.; Cheng, N.; Zhang, J.; Huang, H.; Yuan, Y.; He, X.; Luo, Y.; Huang, K. Nanoscale Cerium Oxide: Synthesis, Biocatalytic Mechanism, and Applications. Catalysts 2021, 11, 1123. https://doi.org/10.3390/ catal11091123

Academic Editor: Aniello Costantini

Received: 31 August 2021

Accepted: 16 September 2021

Published: 18 September 2021

Publisher's Note: MDPI stays neutral with regard to jurisdictional claims in published maps and institutional affiliations.

Copyright: (c) 2021 by the authors. Licensee MDPI, Basel, Switzerland. This article is an open access article distributed under the terms and conditions of the Creative Commons Attribution (CC BY) license (https:// creativecommons.org/licenses/by/ $4.0 /)$.

\begin{abstract}
Nanoscale cerium oxide has excellent catalytic performance due to its unique surface properties and has very important applications in various fields. In this paper, the synthesis methods, catalytic mechanism and activity regulation of nanoscale cerium oxide in recent years are reviewed. Secondly, the application of cerium oxide in the detection of organic and inorganic molecules is summarized, and its latest progress and applications in antibacterial, antioxidant and anticancer are discussed. Finally, the future development prospect of nanoscale cerium oxide is summarized and prospected.
\end{abstract}

Keywords: nanoscale cerium oxide; synthesis; catalytic mechanism; applications

\section{Introduction}

In recent years, research on nanoscale cerium oxide has become increasingly extensive. Ce is a rare earth metal and type of lanthanide in the periodic table. Due to its unique electronic configuration, it has attracted great attention in physics, chemistry, biology, and so on $[1,2]$. Due to the large surface volume ratio of nanomaterials, the surface of nanoscale cerium oxide has a high content of $\mathrm{Ce}^{3+}$. Atomic oxygen can move freely to fill oxygen vacancies and quickly produce surface vacancies. This property of nanoscale cerium oxide leads to the mutual conversion between the oxidation states of $\mathrm{Ce}^{3+}$ and $\mathrm{Ce}^{4+}$. The surface of nanoscale cerium oxide has many active sites, which is beneficial to the redox reaction $[3,4]$.

In addition, because of its oxygen buffering capacity, nanoscale cerium oxide can regenerate itself to the original $\mathrm{Ce}^{3+}$ state [5]. In biological applications, nanoscale cerium oxide is mainly used to scavenge excess reactive oxygen species (ROS) and reactive nitrogen species (RNS), produced in human cells by imitating natural antioxidant enzymes, such as superoxide dismutase (SOD) and catalase (CAT), as well as hydroxyl and nitric oxide free radicals. However, in some cell studies performed under physiological conditions, a pro-oxidative effect due to severe oxidative stress has also been observed [6-8]. Some studies have shown that nanoscale cerium oxide has no catalytic activity on cells [9-11]. It can selectively inhibit tumor cells without affecting normal cells [12,13]. In these studies, the differences in the biological effects of nanoscale cerium oxide are largely due to the differences in the physical, chemical and surface properties of nanoscale cerium oxide synthesized by different methods [14].

This article also mentions some physical, chemical and biological synthesis methods, such as the hydrothermal method, chemical precipitation method, sol-gel method, and 
spray reaction method [15-18]. Additionally, types of nanoscale cerium oxide mimetic enzymes and their activity regulation methods are presented. In addition, this paper also discusses the application of nanoscale cerium oxide in organic and inorganic molecular detection [19-21], metal ions detection [22,23], antibacterial [24-26], antioxidant [27-30] and anticancer [31-35] activities.

\section{Synthesis Method}

Nanoscale cerium oxide can be synthesized by precipitation method [36], hydrothermal method [37], combustion method, decomposition method, oxidation and wet synthesis method, solvothermal method, green/bio directed synthesis, sonochemical method [38], microwave assisted method, micro-emulsion method [39], sol-gel method [40], and so on. Different synthesis methods can produce nanoscale cerium oxide with different forms, shapes and sizes, such as nanoclusters, octahedrons, cube, and rod shapes, as shown in Figure 1 [41]. Different size and surface morphologies have different effects on its physical and chemical properties [42]. Therefore, it is particularly important to select the appropriate synthesis method according to the specific needs of the experiment for subsequent experimental investigation.

(a)

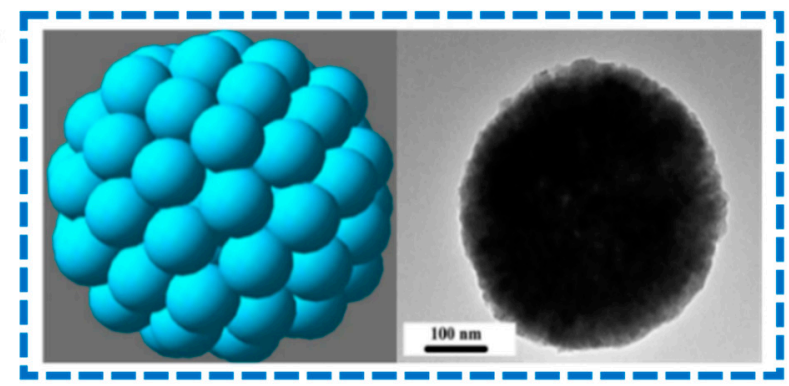

(c)

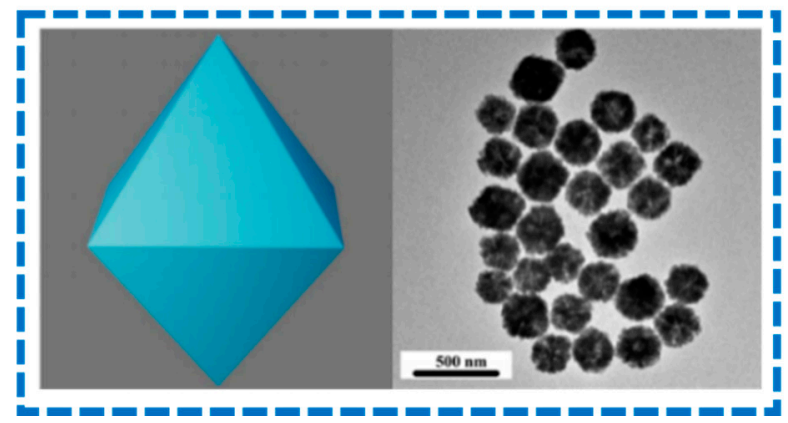

(b)

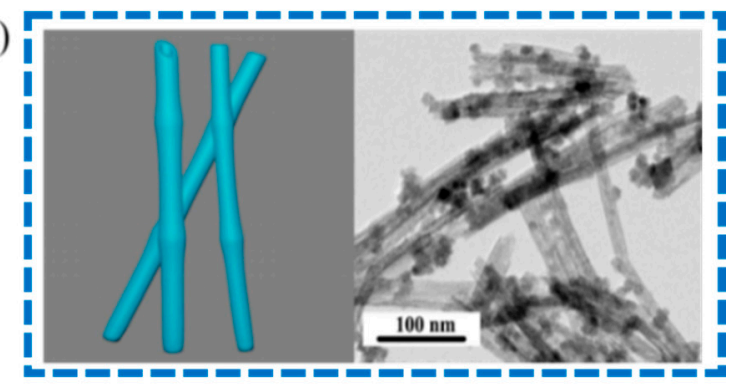

(d)

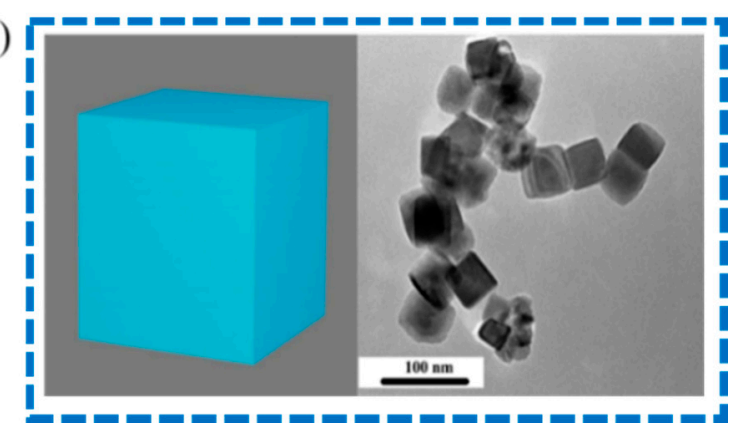

Figure 1. Scheme and transmission electron microscopy (TEM) images of nanoscale cerium oxide with different morphologies [41]. (a) Nanosphere. (b) Stick. (c) Octahedron. (d) Cube. Copyright 2018 John Wiley and Sons.

\section{Mimics of Enzyme-Like Activity}

The biomimetic activity of nanoscale cerium oxide is attributed to the self-regeneration cycle of $\mathrm{Ce}^{3+} / \mathrm{Ce}^{4+}$ and the oxygen vacancies on the surface of nanoscale cerium oxide. Nanoscale cerium oxide can mimic the properties of key natural antioxidant enzymes such as catalase, oxidase, peroxidase, and superoxide dismutase [43].

\subsection{Superoxide Dismutase}

The natural superoxide dismutase can catalyze the superoxide anion radical disproportionation to produce oxygen and hydrogen peroxide. The catalytic effect of SOD is realized through the electron gain and loss between $\mathrm{Mn}^{+1}$ (oxidized state) and $\mathrm{Mn}$ (reduced state).

A higher $\mathrm{Ce}^{3+} / \mathrm{Ce}^{4+}$ ratio on the surface of nanoscale cerium oxide corresponds to a higher SOD-mimicking activity. When the $\mathrm{Ce}^{3+} / \mathrm{Ce}^{4+}$ ratio decreases, the SOD-mimicking activity is inhibited and transformed into catalase/peroxidase-mimicking activity [44,45]. According to the known SOD reaction mechanism, Cassandra Korsvik [46] and coworkers 
proposed that the catalytic effect of nanoscale cerium oxide on superoxide disproportionation in $50 \mathrm{mM}$ Tris- $\mathrm{HCl}$ ( $\mathrm{pH} 7.5$ ) is as follows:

$$
\begin{gathered}
\mathrm{M}^{(\mathrm{n}+1)+}-\mathrm{SOD}+\mathrm{O}_{2}^{\bullet-} \rightarrow \mathrm{M}^{\mathrm{n}+}-\mathrm{SOD}+\mathrm{O}_{2} \\
\mathrm{M}^{\mathrm{n}+}-\mathrm{SOD}+\mathrm{O}_{2}^{\bullet-}+2 \mathrm{H}^{+} \rightarrow \mathrm{M}^{(\mathrm{n}+1)+}-\mathrm{SOD}+\mathrm{H}_{2} \mathrm{O}_{2}
\end{gathered}
$$

The overall activity of nanoscale cerium oxide is significantly dependent on the ratio of $\mathrm{Ce}^{3+} / \mathrm{Ce}^{4+}$, which can provide insight into pro-oxidation and antioxidant activity of nanoscale cerium oxide.

\subsection{Peroxidase}

Natural peroxidase is a marker enzyme of peroxisome. Its active center is iron porphyrin structure, which can catalyze substrate oxidation with hydrogen peroxide as electron acceptor and decompose hydrogen peroxide into water at the same time.

The peroxidase-mimicking characteristics of nanoscale cerium oxide have attracted great attention in recent years [47]. Zhang and coworkers [48] successfully synthesized four kinds of nanoscale cerium oxide, and used them as mimics of peroxidase in $0.2 \mathrm{~mol} / \mathrm{L}$ $\mathrm{CH}_{3} \mathrm{COONa}(\mathrm{pH}$ 4.0). The results show that the catalytic activity is related to the specific surface area and surface oxygen content, since the surface defects are mainly oxygen vacancies that control the oxygen supply to the reaction site. Increasing the concentration of $\mathrm{Ce}^{3+}$ on the surface of nanoscale cerium oxide is beneficial for mimicking the activity of peroxidase.

Most of the peroxidase mimics based on transition metal oxide materials come from metal ions with catalytic activity based on hydrogen peroxide, and their mechanism is similar to that of the Fenton reaction [49].

$$
\begin{gathered}
\mathrm{Ce}^{3+}+\mathrm{H}_{2} \mathrm{O}_{2}+\mathrm{H}^{+} \rightarrow \mathrm{Ce}^{4+}+\mathrm{OH}^{\bullet}+\mathrm{H}_{2} \mathrm{O} \\
\mathrm{OH}^{\bullet}+\mathrm{H}_{2} \mathrm{O}_{2} \rightarrow \mathrm{HO}_{2}^{\bullet}+\mathrm{H}_{2} \mathrm{O} \\
\mathrm{Ce}^{4+}+\mathrm{HO}_{2}^{\bullet} \rightarrow \mathrm{O}_{2}+\mathrm{Ce}^{3+}+\mathrm{H}^{+}
\end{gathered}
$$

This discovery provides Ce-containing materials with the potential to be used as peroxidase mimics. Xue Jiao and coworkers directly proved that nanoscale cerium oxide synthesized by a simple hydrothermal method has peroxidase-like activity, and developed a simple colorimetric method for glucose detection [50]. Tian and coworkers synthesized porous nanoscale cerium oxide with a large specific surface area and high surface $\mathrm{Ce}^{3+}$ content. This nanoscale cerium oxide showed unique peroxidase activity. They believe that the peroxidase-like activity of nanoscale cerium oxide comes from surface $\mathrm{Ce}^{3+}$ [48].

Thus, the potential of using porous nanoscale cerium oxide as an artificial enzyme mimicking peroxidase has been described [32]. Based on nanoscale cerium oxide has the ability to mimic peroxidase, it can be used in biomedical, environmental monitoring, pesticide residues, metal ion detection and other fields.

\subsection{Catalase}

Natural catalase is a conjugated enzyme with iron porphyrin as the auxiliary group and a marker enzyme of peroxisome. Catalase is responsible for the degradation of $\mathrm{H}_{2} \mathrm{O}_{2}$, as $\mathrm{H}_{2} \mathrm{O}_{2}$ is a powerful and potentially harmful oxidant. However, the specific mechanism of catalase is unknown [32]. Recent studies have shown that [51] nanoscale cerium oxide can mimic catalase and catalyze the decomposition of hydrogen peroxide into water and oxygen. It can protect cells from oxidative stress caused by reactive oxygen species. $\mathrm{Ce}^{4+}$ has catalase-like activity and can convert $\mathrm{H}_{2} \mathrm{O}_{2}$ into $\mathrm{O}_{2}$ and $\mathrm{H}^{+}$, changing the $\mathrm{Ce}^{4+}$ valence state to $\mathrm{Ce}^{3+}$ (with the corresponding changes in oxygen vacancies), and adopting the original $\mathrm{CeO}_{2} \mathrm{NP}$ state in phosphate buffers ( $\mathrm{pH}$ 7.4) [52]. Baoliang Zhang and coworkers [41] found that nanoscale cerium oxide has mimicked the activity of superoxide dismutase and catalase because of its reversible switching ability from $\mathrm{Ce}^{3+}$ to $\mathrm{Ce}^{4+}$ and 
high surface oxygen mobility. $\mathrm{Ce}^{3+}$ can reduce $\mathrm{H}_{2} \mathrm{O}_{2}$ to $\mathrm{H}_{2} \mathrm{O}$, while $\mathrm{Ce}^{4+}$ can oxidize $\mathrm{H}_{2} \mathrm{O}_{2}$ to $\mathrm{HOO}^{\bullet}$ and then $\mathrm{O}_{2}$. From these considerations, Ivana Celardo and coworkers [53] proposed a nanoscale cerium oxide model simulating the reaction mechanism of catalase, which is summarized as follows:

$$
\begin{gathered}
2 \mathrm{Ce}^{3+}+\mathrm{H}_{2} \mathrm{O}_{2}+2 \mathrm{H}^{+} \rightarrow 2 \mathrm{H}_{2} \mathrm{O}+2 \mathrm{Ce}^{4+} \\
\mathrm{Ce}^{4+}+\mathrm{H}_{2} \mathrm{O}_{2} \rightarrow \mathrm{Ce}^{3+}+\mathrm{H}^{+}+\mathrm{HOO}^{\bullet} \\
\mathrm{Ce}^{4+}+\mathrm{HOO}^{\bullet} \rightarrow \mathrm{Ce}^{3+}+\mathrm{O}_{2}+\mathrm{H}^{+} \\
2 \mathrm{Ce}^{4+}+\mathrm{H}_{2} \mathrm{O}_{2} \rightarrow 2 \mathrm{Ce}^{3+}+\mathrm{O}_{2}+2 \mathrm{H}^{+}
\end{gathered}
$$

Summing reactions (6) and (7) and (8) and (9) results in reaction (10)

$$
2 \mathrm{H}_{2} \mathrm{O}_{2} \rightarrow \mathrm{O}_{2}+\mathrm{H}_{2} \mathrm{O}_{2}
$$

We can attribute the catalase-mimicking activity to the existence of both $\mathrm{Ce}^{3+}$ and $\mathrm{Ce}^{4+}$ sites on the material surface, which opens a new door for the development of inorganic materials showing redox state-dependent enzyme mimicking activity.

\subsection{Oxidase}

Natural oxidase is the main enzyme of peroxisome, accounting for about half of the total peroxisome, which catalyzes the oxidation of substrates and reduces oxygen to water. Nanoscale cerium oxide has attracted great attention because of its oxidase-like activity at $30^{\circ} \mathrm{C}$ in sodium acetate (pH 4.8) [54]. Can Xu and coworkers [32] found that oxidase-mimicking activity involves molecular oxygen as an electron acceptor. Peng and coworkers [55] proposed that nanoscale cerium oxide can simulate the activity of oxidase and is a kind of nanoparticle oxidant. However, it is completely dissolved after reduction under acidic conditions. Nevertheless, nanoscale cerium oxide as an oxidation catalyst has been widely developed and plays an important role in many fields. For example, nanoscale cerium oxide catalyzes the conversion of oxides such as CO and NOx. The catalytic process mainly includes the following three steps: [56],

$$
\begin{gathered}
2 \mathrm{NO}_{\mathrm{x}} \rightarrow \mathrm{xO}_{2}+\mathrm{N}_{2} \\
2 \mathrm{CO}+\mathrm{O}_{2} \rightarrow 2 \mathrm{CO}_{2} \\
\mathrm{C}_{\mathrm{x}} \mathrm{H}_{2 \mathrm{x}+2}+[(3 \mathrm{x}+1) / 2] \mathrm{O}_{2} \rightarrow \mathrm{xCO}_{2}+(\mathrm{x}+1) \mathrm{H}_{2} \mathrm{O}
\end{gathered}
$$

In the oxidation of $\mathrm{CO}$ and $\mathrm{C}_{\mathrm{x}} \mathrm{H}_{2 \mathrm{x}+2}$, nanoscale cerium oxide plays a role similar to that of oxidase. Based on the excellent oxidase activity of nanoscale cerium oxide, it will be applied in biomedicine, pesticide residue detection, heavy metal ion detection and other fields.

\subsection{Phosphatase}

Phosphatase is an enzyme that dephosphorylates the corresponding enzyme from the substrate by hydrolyzing the phosphate monomer to remove the phosphate group from the substrate molecule and to produce phosphate ions and free hydroxyl groups.

Alkaline phosphatase plays a key role in many cellular functions through protein dephosphorylation. Many biomolecules related to phosphate can be hydrolyzed by nanoscale cerium oxide. The dephosphorization activity of nanoscale cerium oxide depends on the existence of $\mathrm{Ce}^{3+}$. When $\mathrm{Ce}^{3+}$ is converted to $\mathrm{Ce}^{4+}$, the dephosphorylation activity of nanoscale cerium oxide is inhibited. Can $\mathrm{Xu}$ and coworkers [32] found that nanoscale cerium oxide can mimic phosphatase activity. The phosphate group in the substrate is removed by hydrolyzing phosphate monoester to a phosphate ion. Ce is the only rare earth element that can be oxidized to tetravalent state, so it has received a great deal of attention. Some studies $[57,58]$ have found that nanoscale cerium oxide can effectively mediate the 
dephosphorylation of phosphopeptides under $25^{\circ} \mathrm{C}$ under physiological conditions. As nanoscale cerium oxide is a strong Lewis acid, its dephosphorization is mainly attributed to the activation of Lewis acids coordinated by phosphoryl oxygen and $\mathrm{Ce}^{4+}$ and the nucleophilic activation of hydroxyl coordination with $\mathrm{Ce}^{4+}$

$$
\mathrm{Ce}^{3+}+\mathrm{O}_{2} \rightarrow \mathrm{Ce}^{4+}+\mathrm{O}_{2}^{\bullet-}
$$

Based on nanoscale cerium oxide's ability to mimic phosphatase, it can not only achieve phosphorylation of phosphatase substrate, but also dephosphorize DNA, which opens up a new research direction for molecular biology.

\section{Activity Regulation}

The catalytic activity of nanozymes can be changed by adjusting several key factors such as size, morphology, composition, surface modification and surrounding environment [14]. In this part, the effects of these factors on the activity of nanoscale cerium oxide were summarized and discussed, respectively.

\subsection{Size}

As the most important parameter affecting the activity of nanomaterials, many studies have proved the influence of size on the activity of simulated enzymes of nanomaterials [14]. Generally speaking, the smaller the size of nanomaterials, the stronger their catalytic performance. This is because the smaller the size, the larger the surface volume ratio, thus exposing more active sites. For example, Aasati and coworkers [59] used nanoscale cerium oxide with a nanometer size of 5-100 $\mathrm{nm}$ to explore the catalytic oxidation rate of substrate $\mathrm{TMB}$, and found that with the increase of nanometer size, the catalytic efficiency decreased. It can be concluded that the size of nanoscale cerium oxide has an important influence on its catalytic performance.

\subsection{Morphology}

The mimic enzyme performance of nanoscale cerium oxide is highly dependent on their morphology, because different morphologies have different exposed surfaces, thus showing different catalytic activities [14]. For example, Miguel Tinoco and coworkers [60] reported for the first time that only nanoscale cerium oxide controlled by morphology showed strong oxidation performance to glycerol without doping any other metals. TEM, Raman and XPS analysis show that crystal morphology plays a key role in the catalytic activity and selectivity of nanoscale cerium oxide. R.Udayabhaskar and coworkers [61] obtained different forms of nanoscale cerium oxide, such as spheres, cubes and rods, by adjusting experimental parameters. Finally, it is found that the catalytic performance of nanoscale cerium oxide is related to its morphology, and its catalytic performance varies with different morphology.

\subsection{Hetero-Atom Doping}

Up to now, hybrid nanomaterials have attracted wide attention because of their clear structure and enhanced performance [62]. Metal-heteroatom doping is an effective way to obtain high-performance mimic enzymes [62]. For example, Chen and coworkers [63] doped copper atoms in nanoscale cerium oxide, and it was proved by scanning transmission electron microscopy, electron energy loss spectrum, infrared spectrum in situ detection characterization and reaction kinetics that the doping of copper atoms can significantly improve its catalytic activity. Serdar Akbayrak and coworkers [64] studied the effects of various oxide supports on the catalytic activity of rhodium nanoparticles in the hydrolysis of ammonia borane to produce hydrogen. In $\mathrm{CeO}_{2}, \mathrm{SiO}_{2}, \mathrm{Al}_{2} \mathrm{O}_{3}, \mathrm{TiO}_{2}, \mathrm{ZrO}_{2}$ and $\mathrm{HfO}_{2}$ as oxide carriers, nanoscale cerium oxide shows higher catalytic activity for rhodium nanoparticles in the hydrolysis of ammonia borane, which means that doping rhodium on the surface of nanoscale cerium oxide can improve its catalytic activity. In addition, Gregory $\mathrm{M}$ and coworkers [65] doped nanoscale cerium oxide carrier with $\mathrm{Al}$, $\mathrm{La}$ and $\mathrm{Zr}$ 
in the synthesis process, and finally found that nanoscale cerium oxide doped with these atoms has higher catalytic activity and selectivity.

\subsection{Surface Modification}

In the process of catalytic oxidation, the main occurrence area is on the surface of nanomaterials, so its catalytic activity will be affected by surface modification [14]. Surface modification mainly includes physical adsorption (such as ions, small molecules, biological macromolecules and polymers) and covalent modification [66]. According to a large number of studies, the catalytic performance of nanoscale cerium oxide is easily affected by surface modification such as surface coating thickness, functional groups and surface charges [62]. For example, Liao and coworkers [19] found that the catalytic performance of nanoscale cerium oxide for TMB oxidation was inhibited in the presence of heparin or deoxyribonucleic acid, mainly because the active sites on the surface of nanoparticles were shielded by these biomolecules, which reduced the catalytic activity of ceria nanozyme. In contrast, Liu and coworkers reported that fluoride $\mathrm{F}^{-}$can effectively increase the oxidase activity of ceria nanozyme by more than 100 times based on strong electronegativity, making its activity close to that of natural oxidase $[67,68]$. In addition, similar to physical adsorption, covalent coating or modification with different ligands affects the catalytic activity of nanoscale cerium oxide by affecting its active site. For example, Aasati and coworkers [59] found that nanoscale cerium oxide modified with polyacrylic acid has stronger oxidase activity than nanoscale cerium oxide modified with dextran. This may be because polyacrylic acid has higher permeability than dextran, and the substrate molecules on the surface are more easily transferred to active sites. Therefore, the surface modification has an important influence on the catalytic performance of nanoscale cerium oxide.

\subsection{Surrounding Environments}

The surrounding environment, such as $\mathrm{pH}$ and temperature, has certain influence on the catalytic performance of nanoscale cerium oxide [14]. The $\mathrm{pH}$ factor plays an important role in the reaction catalyzed by nanoscale cerium oxide. For example, Asati and coworkers [59] found that the simulated oxidase activity of nanoscale cerium oxide is highly dependent on environmental $\mathrm{pH}$, and has the strongest activity in acidic acetate buffer, which can be attributed to the protonation effect of nanoscale cerium oxide at low $\mathrm{pH}[59,69]$. This is based on the fact that nanoscale cerium oxide has strong peroxidase and oxidase activities under acidic conditions and strong SOD and CAT activities under neutral or alkaline conditions [70]. Therefore, the simulated enzyme activity was switched by changing the $\mathrm{pH}$ value of microenvironment.

\section{Applications}

Nanoscale cerium oxides have attracted much attention because of their special bivalent redox system of $\mathrm{Ce}^{3+}$ and $\mathrm{Ce}^{4+}$ and excellent enzyme-like activity [71]. In this paper, the application of nanoscale cerium oxide in organic/inorganic molecular detection, antibacterial activity, antioxidant activity and anticancer activity will be introduced in detail.

\subsection{Organic/Inorganic Molecular Detection}

Based on the excellent enzyme-like activity of nanoscale cerium oxide, it can be used in the detection of organic and inorganic small molecules. For example, RuochenGuo and coworkers [20] studied the interaction between $\mathrm{H}_{2} \mathrm{O}_{2}$ and dextran-coated nanoscale cerium oxide, and found that $\mathrm{H}_{2} \mathrm{O}_{2}$ can act as both an inhibitor and an accelerator in the oxidase activity of nanoscale cerium oxide, that is, $\mathrm{H}_{2} \mathrm{O}_{2}$ can promote the oxidase activity of nanoscale cerium oxide at high concentration, and inhibit its catalytic activity at low concentration. In addition, the inhibitory effect is linearly related to the concentration of $\mathrm{H}_{2} \mathrm{O}_{2}$. Based on these findings, a simple, rapid and sensitive colorimetric method was established for the determination of $\mathrm{H}_{2} \mathrm{O}_{2}$, and its limit of detection (LOD) was $2.5 \mu \mathrm{m}$. 
When coupled with glucose oxidase, the detection limit for glucose is as low as $2 \mu \mathrm{m}$. Therefore, the detection of hydrogen peroxide and glucose can be realized (Figure 2a). In addition, Liao and coworkers [19] based on the adsorption of Heparin (Hep) on the surface of nanoscale cerium oxide, the oxidation ability of nanoscale cerium oxide to $3,3^{\prime}, 5,5^{\prime}$ Tetramethylbenzidine (TMB) decreased in the presence of Hep. Under the optimum conditions, the detection limit of Hep is $20 \mathrm{nM}$. It has been applied to the determination of Hep in medical injection samples and serum samples with satisfactory results (Figure $2 b$ ). Veronica Andre and coworkers [21] reported that an electrochemical sensor for detecting phenolic antioxidants was constructed based on the oxidase-like activity of nanoscale cerium oxide particles. Using nanoscale cerium oxide in sensor design can oxidize phenolic compounds (especially phenolic compounds with o-dihydroxybenzene functional group) into corresponding quinones on the surface of screen-printed carbon electrode. The method can quickly detect common phenolic antioxidants, such as caffeic acid, gallic acid and quercetin. Therefore, it can be seen that nanoscale cerium oxide has great advantages in the detection of organic and inorganic molecules.

In addition, heavy metal ions can enter the human body through the environment, food and other ways, endangering human health. Therefore, it is necessary to develop some rapid, portable and efficient detection technologies to strengthen the detection of metal ions in environment and food [22,72]. Xue Tian and coworkers [22] based on the phosphatase-like activity of nanoscale cerium oxide, combined with chemiluminescence technology, applied it to the detection of $\mathrm{Al}^{3+}$. It is not only proved that nanoscale cerium oxide has a catalytic dephosphorylation effect on CDP-star, but also its activity is affected by $\mathrm{pH}$, and it has considerable phosphatase-like activity under neutral $\mathrm{pH}$ condition. It is also proved that $\mathrm{Al}^{3+}$ can chelate with oxygen atoms in nanoscale cerium oxide structure to form $\mathrm{Al}-\mathrm{O}$, thus inhibiting the activity of nanoscale cerium oxide phosphatase and realizing the chemiluminescence detection of $\mathrm{Al}^{3+}$ (Figure 2a). Solivera and coworkers [23] summarized that nanoscale cerium oxide and its composites have the potential to remove toxic metal ions such as arsenic, fluoride, lead and cadmium from aqueous media. Based on the high surface area, controllable porosity, morphology and abundant functional groups of ceria and composite materials, toxic metal ions can be adsorbed and removed. It can be seen that nanoscale cerium oxide plays an important role in the future application of heavy metal detection.

\subsection{Antibacterial Activity}

Nanoscale cerium oxide is an important antibacterial agent. Compared with other antibacterial drugs, their toxicity to normal cells is relatively low. Based on this advantage, they have been widely used in antibacterial research [26]. For example, nanozyme can produce hydroxyl radical through Fenton-like reaction in the presence of $\mathrm{H}_{2} \mathrm{O}_{2}$, thus killing bacteria. Nanoparticles are selective for bacterial cells largely by artificial means of targeting them. For example, by modifying the surface of nanoparticles with polysaccharides to form polysaccharide shells. The polysaccharide shell can specifically bind to specific lectins on the surface of bacteria, so that nanoparticles can actively target pathogens in vivo. Thus, reducing the damage to the body's normal cells. Qin and coworkers [73] constructed a porous ceria hollow sphere/enzyme nano-reactor by loading glucose oxidase in mesoporous ceria hollow sphere nanozyme. The detection principle based on it is shown in Figure 3. Based on the unique nano-framework, large internal gap and high specific surface area, nontoxic glucose is effectively converted into highly toxic hydroxyl radicals by cascade catalytic reaction in the nano-reactor, thus seriously destroying the cell structure of bacteria and preventing the formation of biofilm. In addition, the generated gluconic acid can lower the local $\mathrm{pH}$ value and further improve the catalytic performance of porous cerium oxide for peroxidase. Synthesizing the above reactions, it can inhibit bacteria. Murillo and coworkers [25] synthesized samples containing Ag-doped $\mathrm{CeO}_{2}$, which showed high antibacterial activity and could inhibit the growth of Escherichia coli, Staphylococcus aureus and Pseudomonas aeruginosa bacteria, while there was no antibac- 
terial activity without silver-doped $\mathrm{CeO}_{2}$. It can be inferred that silver ions can replace part of cerium ions in nanoscale cerium oxide, thus showing satisfactory antibacterial activity. MMLatif and coworkers [24] doped $\mathrm{CeO}_{2}$ with different concentrations of manganese $(\mathrm{Mn})$ and iron $(\mathrm{Fe})$, and tested its antibacterial and antifungal activities. Gram positive test and Gram negative test of Escherichia coli were carried out by Staphylococcus aureus, and antifungal activity was tested by Candida albicans. The experimental results finally found that with the increase of Fe and Mn doping concentration, the ability of nanoscale cerium oxide to inhibit Gram-positive bacteria and Gram-negative bacteria increased, while the antifungal activity decreased gradually.

(a)

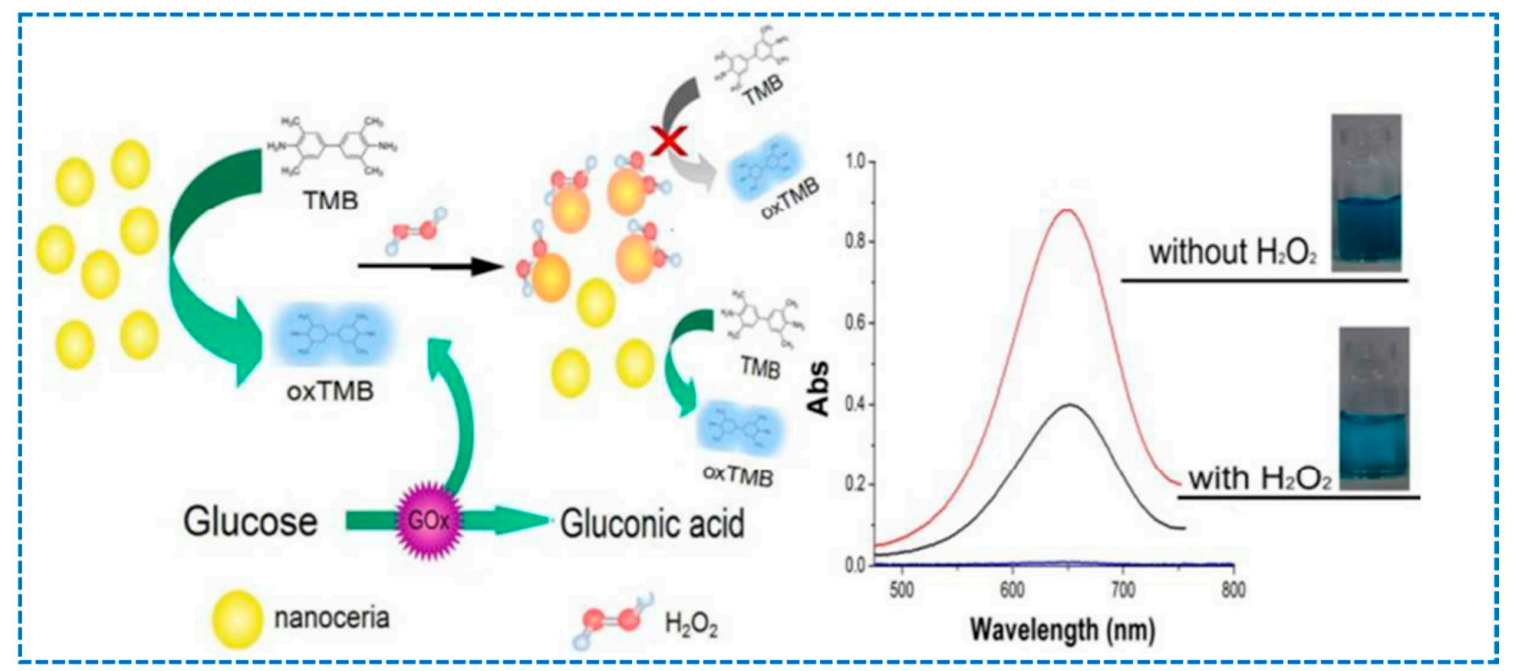

(b)

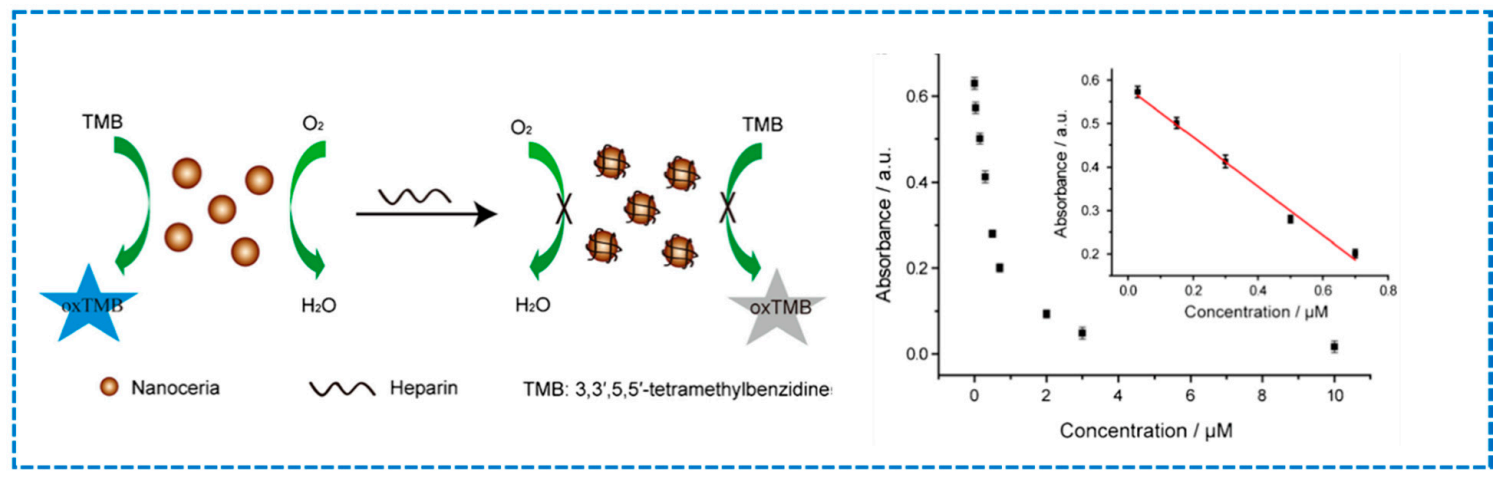

(c)

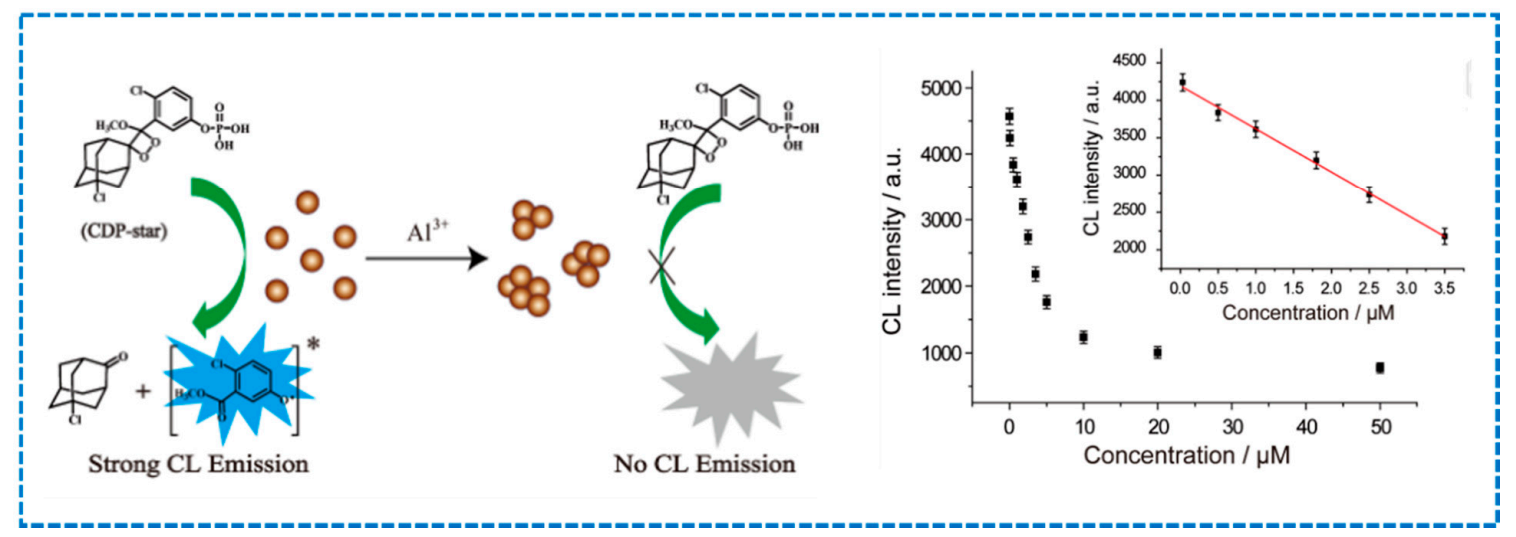

Figure 2. Application of nanoscale cerium oxide in detection of organ/inorganic molecules. (a) Detection of hydrogen peroxide and glucose [20] Copyright 2016 RSC Publishing; (b) heparin detection [19] Copyright 2016 Springer Nature; (c) metal ion detection [22]. Copyright 2019 Elsevier. 


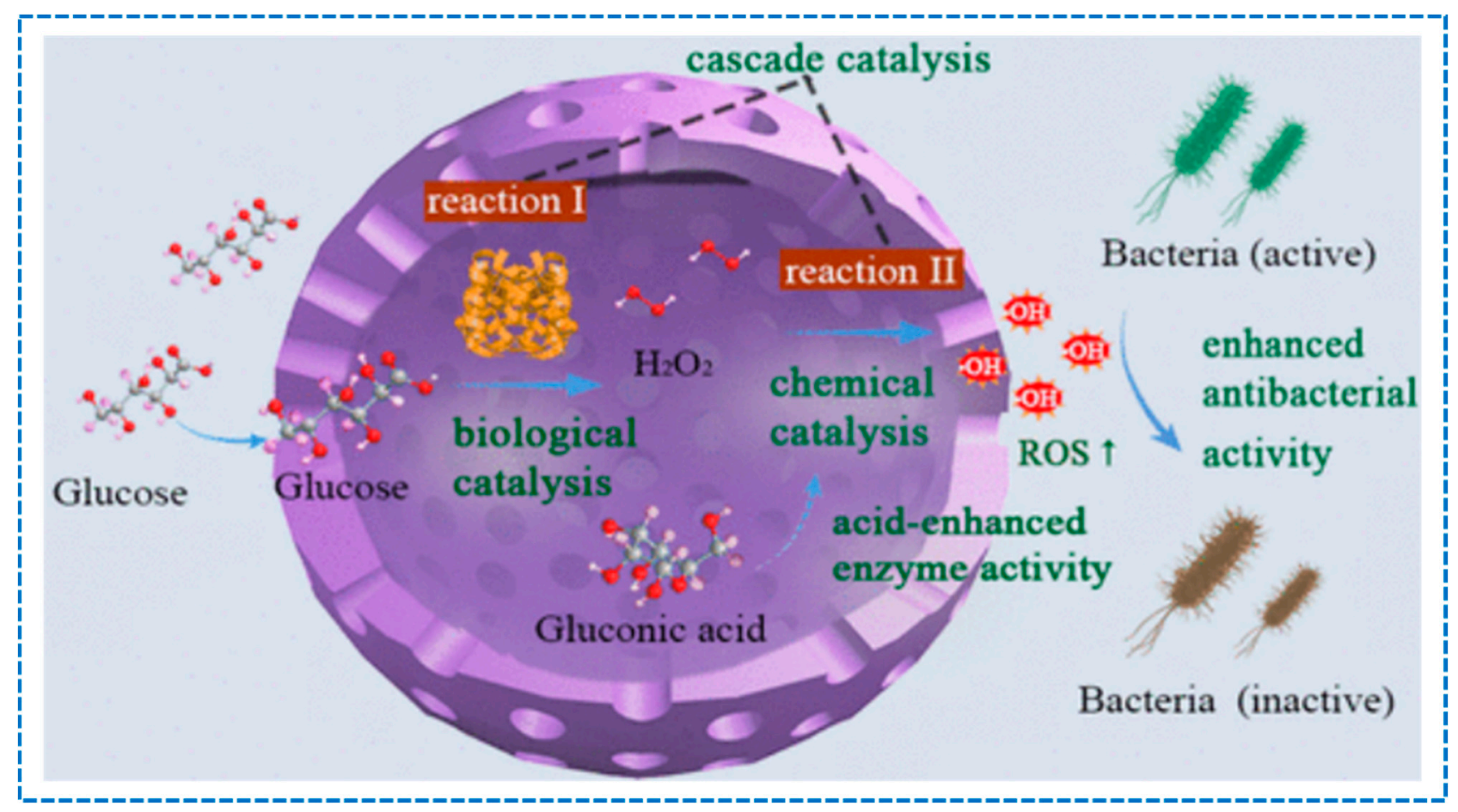

Figure 3. Antibacterial mechanism of nanoscale cerium oxide [73]. Copyright 2021 American Chemical Society.

\subsection{Antioxidant Activity}

Due to the oxidation cycle between $\mathrm{Ce}^{3+}$ and $\mathrm{Ce}^{4+}$ in the nanoscale cerium oxide structure, it shows remarkable antioxidant activity [27]. The antioxidation mechanism of nanoscale cerium oxide is mainly as follows: it enters cells through receptor-mediated endocytosis, and is released into cytoplasm from endocytosis, which shows the effect of promoting oxidation in cells. In normal cells (with physiological $\mathrm{pH}$ ), nanoscale ceria enters the cells by endocytosis to remove active oxygen $\left(\mathrm{O}_{2}, \mathrm{H}_{2} \mathrm{O}_{2}\right.$ or $\left.\mathrm{OH}\right)$, which is due to the simulated activity of SOD and CAT, which shows antioxidant effect and protects normal cells. Das and coworkers [28] studied the antioxidant activity of nanoscale cerium oxide with a size of about $3-5 \mathrm{~nm}$ in a serum-free cell culture model of adult rat spinal cord. Compared with untreated control group, higher cell survival rate and less cell death were observed after treatment with nanoscale cerium oxide. The results indicated that nanoscale cerium oxide could scavenge various free radicals in culture medium and provide neuroprotection for spinal cord neurons of adult rats. In addition, Colon and coworkers [30] studied the radioprotective effect of nanoscale cerium oxide on gastrointestinal epithelium. Finally, it was found that nanoscale cerium oxide can protect human colon cells from radiation-induced oxidative damage by promoting cells to produce superoxide dismutase, which can prove that nano-ceria has potential as a free radical scavenger.

Chen and coworkers [29] based on the previous experimental research, proposed the protective effect and potential mechanism of nanoscale cerium oxide on oxidative damage of endothelial cells (Figure 4). Based on the membrane interaction between nanoscale cerium oxide and endothelial cells, it is absorbed by endocytosis mediated by pores and reticulin. In cytoplasm, nanoscale cerium oxide can remove reactive oxygen species by mimicking the activities of superoxide dismutase and catalase. With the decrease of ROS, mitochondrial transmembrane potential increases, which can effectively prevent apoptosis induced by oxidative stress. Nanoscale cerium oxide can promote oxidation and antioxidation to different cells. The main reason is the change of oxidation-reduction potential of $\mathrm{Ce}^{3+} / \mathrm{Ce}^{4+}$ on its surface. Madaml and coworkers [74] explored the antioxidant properties of nanoscale cerium oxide with a size of 3-7 nm in E. coli. It was found that uncoated nanoscale ceria and nanoscale ceria coated with glycine have antioxidant properties in 
E. coli, while PEG-coated nanoscale cerium oxide has oxidation-promoting properties due to the difference of surface chemistry and redox potential.

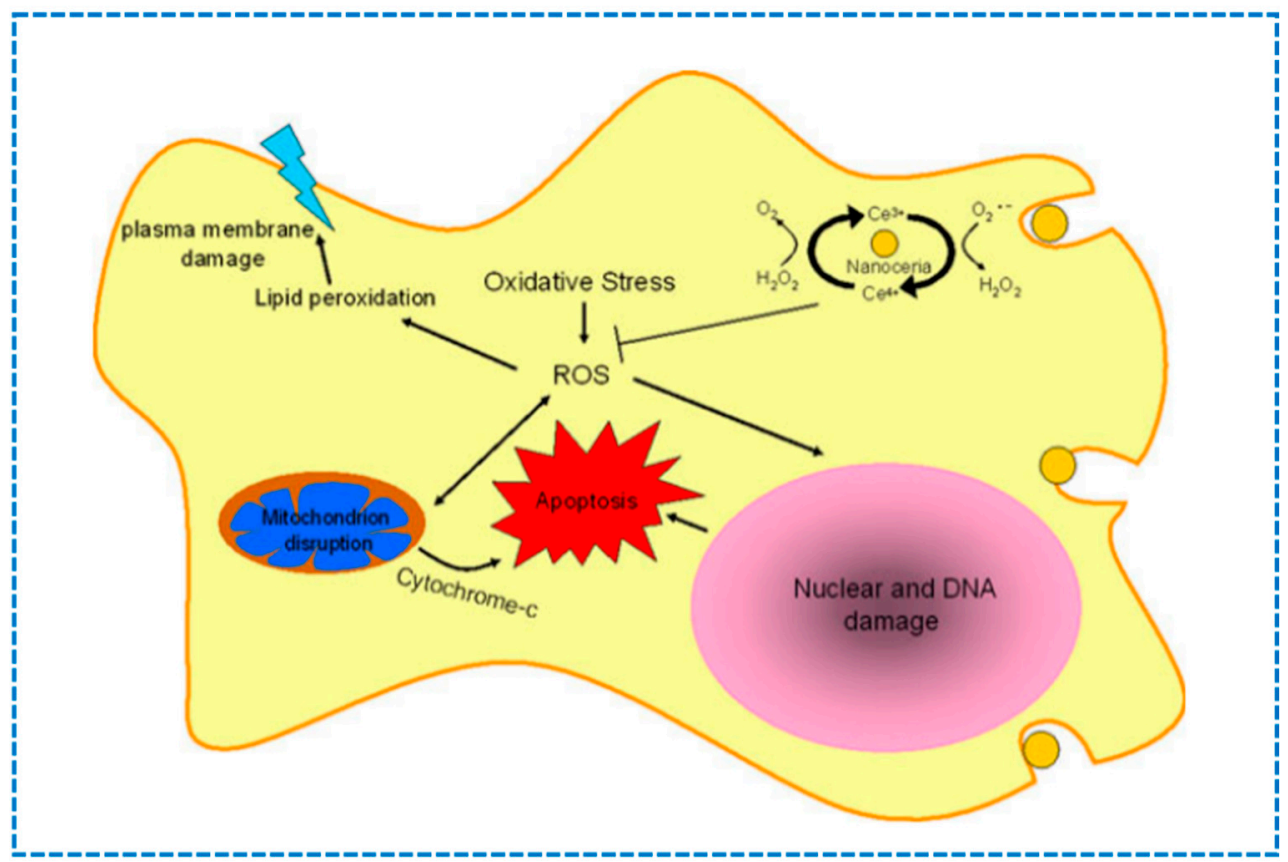

Figure 4. Antioxidant mechanism of nanoscale cerium oxide [29]. Copyright 2013 MDPI AG.

\subsection{Anticancer Activity}

In addition to antibacterial and antioxidant activities, nanoscale cerium oxide also has strong anticancer potential. The main inhibition mechanism is to kill cancer cells by inducing the formation of reactive oxygen species [31]. Cancer cells are more tolerant to lower $\mathrm{pH}$ than normal cells due to the increase of glycolysis and lactic acid production rate. The antioxidation performance of nanoscale cerium oxide is lost under low $\mathrm{pH}$ condition, which makes ROS produced in the system cause oxidative stress and induce cancer cell apoptosis, thus having anticancer ability [32]. Lin and coworkers [33] studied the anticancer effect of nanoscale cerium oxide with a size of $20 \mathrm{~nm}$ on human lung cancer cells. After continuous treatment with different concentrations of nanoscale cerium oxide for 24,48 and $72 \mathrm{~h}$, it can be observed that with the extension of treatment time and the increase of concentration, the toxicity of nanoscale cerium oxide to lung cancer cells through oxidative stress is also stronger. In addition, the experimental results of Nourmohammadi and coworkers [34] and Jana and coworkers [35] all prove that the anticancer ability of cerium oxide is positively correlated with its dosage and treatment time, and verify that high-dose nanoscale cerium oxide has low toxicity to normal cells. The above experimental results also laid a foundation for biomedical research of nanoscale cerium oxide.

Therefore, nanoscale cerium oxide is a kind of nanometer material with anticancer potential and can be used as an anticancer therapeutic agent. At the same time, some studies have also used it as a nanocarrier or scaffold for biomedical applications. For example, $\mathrm{Xu}$ and coworkers [75] designed a multifunctional CeONP-capped mesoporous silica nanoparticle (MSN) anticancer drug delivery system (Figure $5 a, b)$. They synthesized $\beta$-cyclodextrin modified nanoscale cerium oxides and ferrocene functionalized MSN. Under physiological conditions, $\beta$-cyclodextrin modified nanoscale cerium oxide entered lung cancer (A549) cells by interacting with ferrocene functionalized MSN and lysosome pathway ( $\mathrm{pH} 4.5-5.0)$. The ferrocenyl moieties were oxidized to ferrocenium ions by CeONP lids, which triggered the uncapping of CeONP and caused the drug release. Moreover, nanoscale cerium oxide has a certain toxic effect on cells under acidic conditions, so it shows a synergistic anticancer effect with anticancer drugs. And they also designed a CeONP-terminated $\mathrm{H}_{2} \mathrm{O}_{2}$-responsive drug release system for $\mathrm{AD}$ treatment (Figure $5 \mathrm{c}$ ). 
They combined the anti-aggregation performance of metal chelating agent and the antioxidation performance of nanoscale cerium oxide in one system. The two-in-one dual-function platform can effectively inhibit the formation of $A \beta$, reduce ROS in cells, and protect cells from $A \beta$-related toxicity, thus effectively realizing the treatment of diseases.

(a)

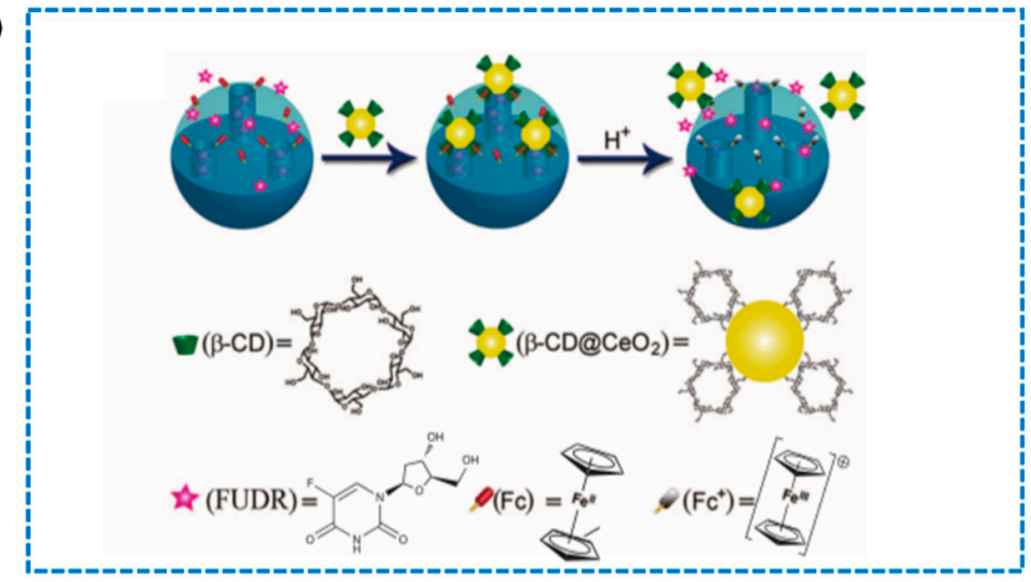

(b)

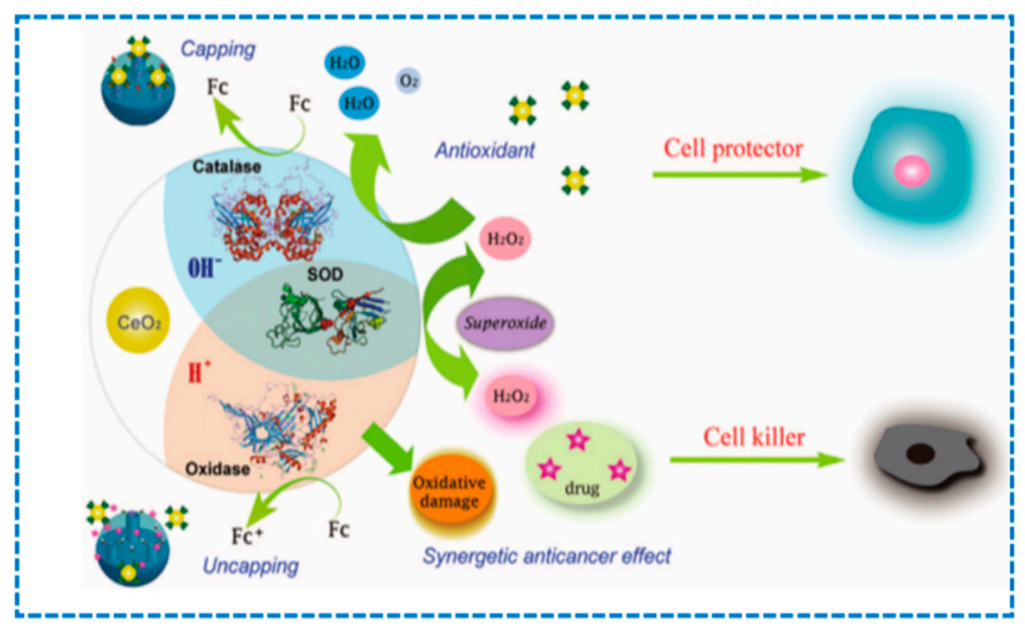

(c)

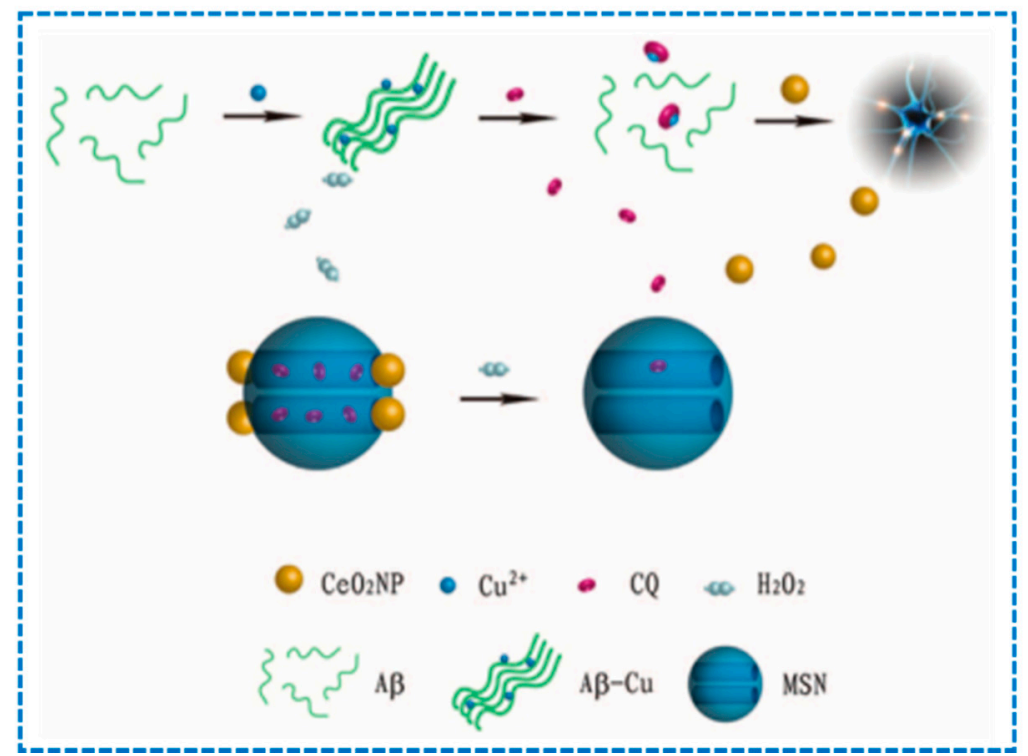

Figure 5. Design of nanoscale cerium oxide anticancer drug carrier. (a) Nanoscale cerium oxide nanocarrier framework for anticancer drugs [75]; (b) anticancer mechanism [75]; (c) anti-Alzheimer's nanocarrier framework [75]. Copyright 2013 Royal Society of Chemistry 


\section{Conclusions and Perspectives}

Firstly, nanoscale cerium oxide can be synthesized by precipitation method, hydrothermal method, combustion method, decomposition method, oxidation and wet synthesis method, solvothermal method, green/bio directed synthesis, sonochemical method, microwave assisted method, micro-emulsion method, sol-gel method, and so on.

Furthermore, nanoscale cerium oxide has the catalytic ability to mimic superoxide dismutase, peroxidase, oxidase, catalase and phosphatase. The catalytic activity of nanoscale cerium oxide can be adjusted by size, morphology, composition, surface modification, and surrounding environment methods to improve its application in detection.

In addition, nanoscale cerium oxide is widely used in the detection of organic/inorganic molecules, and has application potential in antibacterial, antioxidant and anticancer aspects.

In the future, how to improve the detection performance of nanoscale cerium oxide, and how to improve the sensitivity and specificity in the detection process are also the key research directions in future design. Nanoscale cerium oxides have great development and utilization value, and it is believed that they can be fully applied to various research fields in the future.

Author Contributions: G.S. formulated the aims, wrote and revised the manuscript. N.C. designed the ideas, wrote and revised the manuscript. J.Z. researched and summarized the literature. H.H. researched and summarized the literature. Y.Y. researched and summarized the literature. X.H. researched and summarized the literature. K.H. formulated the aims, discussed the ideas. Y.L. designed the ideas, got the financial support for the project leading to this publication. All authors have read and agreed to the published version of the manuscript.

Funding: We would like to thank the National Key Research and Development Program "Research on Food Safety Emergency and Major Incident Emergency Command and Decision-making Technology" (2018YFC1603704) and Shandong Provincial Key Research and Development Program (2019JZZY011014). Nan Cheng would like to thank the 2115 Talent Development Program of China Agricultural University.

Conflicts of Interest: The authors declare that they have no competing interests.

\section{References}

1. Das, S.; Dowding, J.M.; Klump, K.E. Cerium oxide nanoparticles: Applications and prospects in nanomedicine. Nanomed. Nanotechnol. Biol. Med. 2013, 8, 1483-1508. [CrossRef]

2. Bryant, N.; Monique, J.; Marlon, W. Antioxidant Cerium Oxide Nanoparticles in Biology and Medicine. Antioxidants 2016, 5, 15. [CrossRef]

3. Karakoti, A.; Singh, S.; Dowding, J.M. Redox-active radical scavenging nanomaterials. Chem. Soc. Rev. 2010, 39, 4422-4432. [CrossRef]

4. Fukui, K.I.; Namai, Y.; Iwasawa, Y. Imaging of surface oxygen atoms and their defect structures on $\mathrm{CeO}_{2}(111)$ by noncontact atomic force microscopy. Appl. Surf. Sci. 2002, 188, 252-256. [CrossRef]

5. Dowding, J.M.; Das, S.; Kumar, A. Cellular interaction and toxicity depend on physicochemical properties and surface modification of redox-active nanomaterials. ACS Nano 2013, 7, 4855-4868. [CrossRef] [PubMed]

6. Yokel, R.A.; Florence, R.L.; Unrine, J.M.; Tseng, M.T.; Graham, U.M.; Wu, P.; Grulke, E.A.; Sultana, R.; Hardas, S.S.; Butterfield, D.A. Biodistribution and oxidative stress effects of a systemically-introduced commercial ceria engineered nanomaterial. Nanotoxicology 2009, 3, 234-248. [CrossRef]

7. Ma, J.Y.; Zhao, H.; Mercer, R.R. Cerium oxide nanoparticle-induced pulmonary inflammation and alveolar macrophage functional change in rats. Nanotoxicology 2011, 5, 312-325. [CrossRef] [PubMed]

8. Hussain, S.; Al-Nsour, F.; Rice, A.B. Cerium dioxide nanoparticles induce apoptosis and autophagy in human peripheral blood monocytes. ACS Nano 2012, 6, 5820. [CrossRef] [PubMed]

9. Zhou, X.; Wong, L.L.; Karakoti, A.S. Nanoceria Inhibit the Development and Promote the Regression of Pathologic Retinal Neovascularization in the Vldlr Knockout Mouse. PLoS ONE 2011, 6, e16733. [CrossRef] [PubMed]

10. Thill, A.; Zeyons, O.; Spalla, O. Cytotoxicity of $\mathrm{CeO}_{2}$ Nanoparticles for Escherichia coli. Physico-Chemical Insight of the Cytotoxicity Mechanism. Environ. Sci. Technol. 2006, 40, 6151-6156. [CrossRef] [PubMed]

11. Singh, N.; Cohen, C.A.; Rzigalinski, B.A. Treatment of Neurodegenerative Disorders with Radical Nanomedicine. Ann. N. Y. Acad. Sci. 2010, 1122, 219-230. [CrossRef] [PubMed]

12. Babu, S.; Cho, J.H.; Dowding, J.M. Multicolored redox active upconverter cerium oxide nanoparticle for bio-imaging and therapeutics. Chem. Commun. 2010, 46, 6915-6917. [CrossRef] [PubMed] 
13. Renu, G.; Rani, V.V.D.; Nair, S.V.; Subramanian, K.R.V.; Lakshmanan, V.K. Development of Cerium Oxide Nanoparticles and Its Cytotoxicity in Prostate Cancer Cell. Adv. Sci. Lett. 2012, 6, 17-25. [CrossRef]

14. Asati, A.; Santra, S.; Kaittanis, C. Oxidase-like activity of polymer-coated cerium oxide nanoparticles. Angew. Chem. 2009, 121, 2344-2348. [CrossRef]

15. Xue, S.Q. The chemical preparation method and application of nano-dioxide research. Chem. Technol. Dev. 2014, 43, 38-40.

16. Huang, X.Y.; Li, L.H.; Zhang, J.S.; Yang, P. Research progress on preparation and application of nano cerium oxideApplied. Chem. Ind. 2014, 43, 1701-1704.

17. Zhang, J.C.; Zhang, Y.J.; Tan, S.L.; Zheng, H.D. Preparation and application of nano-cerium oxide. Preparation and ozonation application of cerium dioxide nano-catalyst. Mod. Chem. 2004, 17, 233-235.

18. Dong, Y.M.; Wu, L.N.; He, A.Z.; Jiang, P.P. Preparation and ozonation application of cerium dioxide nano-catalyst. Environ. Sci. Technol. 2012, 35, 212-214.

19. Liao, H.; Liu, Y.; Chen, M. A colorimetric heparin assay based on the inhibition of the oxidase mimicking activity of cerium oxide nanoparticles. Microchim. Acta 2019, 186, 1-6. [CrossRef] [PubMed]

20. Guo, R.; Wang, Y.; Yu, S.; Zhu, W.; Zheng, F.; Liu, W.; Wang, J. Dual role of hydrogen peroxide on the oxidase-like activity of nanoceria and its application for colorimetric hydrogen peroxide and glucose sensing. RSC Adv. 2016, 6, 59939-59945. [CrossRef]

21. Andrei, V.; Sharpe, E.; Vasilescu, A.; Andreescu, S. A single use electrochemical sensor based on biomimetic nanoceria for the detection of wine antioxidants. Talanta 2016, 156-157, 112-118. [CrossRef]

22. Xue, T.A.; Hong, L.A.; Min, W.B. Highly sensitive chemiluminescent sensing of intracellular Al3+ based on the phosphatase mimetic activity of cerium oxide nanoparticles—ScienceDirect. Biosens. Bioelectron. 2020, 152, 112027.

23. Olivera, S.; Chaitra, K.; Venkatesh, K. Cerium dioxide and composites for the removal of toxic metal ions. Environ. Chem. Lett. 2018, 16, 1233-1246. [CrossRef]

24. Latif, M.M.; Amin, F.; Ajaz-Un-Nabi, M.; Khan, I.-U.; Sabir, N. Synthesis and antimicrobial activities of manganese (Mn) and iron (Fe) Co-Doped cerium dioxide $\left(\mathrm{CeO}_{2}\right)$ Nanoparticles. Phys. B Condens. Matter 2020, 600, 412562. [CrossRef]

25. De Matos Rodrigues, M.H.; Borges, K.C.M.; de Cássia Santos, M.R.; de Carvalho Barros, J.J.; de Fátima Gonçalves, R.; Motta, F.V.; Godinho, M. Synthesis, characterization and in vitro antimicrobial prospecting of silver-doped ceria. J. Therm. Anal. Calorim. 2020, 139, 849-854. [CrossRef]

26. Thakur, N.; Manna, P.; DAS, J. Synthesis and biomedical applications of nanoceria, a redox active nanoparticle. J. Nanobiotechnol. 2019, 17, 1-27. [CrossRef] [PubMed]

27. Karakoti, A.S.; Monteiro-Riviere, N.A.; Aggarwal, R.; Davis, J.P.; Narayan, R.J.; Self, W.T.; Seal, S. Nanoceria as antioxidant: Synthesis and biomedical applications. JOM 2008, 60, 33-37. [CrossRef] [PubMed]

28. Das, M.; Patil, S.; Bhargava, N. Auto-catalytic ceria nanoparticles offer neuroprotection to adult rat spinal cord neurons. Biomaterials 2007, 28, 1918. [CrossRef] [PubMed]

29. Chen, S.; Hou, Y.; Cheng, G.; Zhang, C.; Wang, S.; Zhang, J. Cerium Oxide Nanoparticles Protect Endothelial Cells from Apoptosis Induced by Oxidative Stress. Biol. Trace Elem. Res. 2013, 154, 156-166. [CrossRef]

30. Colon, J.; Hsieh, N.; Ferguson, A. Cerium oxide nanoparticles protect gastrointestinal epithelium from radiation-induced damage by reduction of reactive oxygen species and upregulation of superoxide dismutase 2. Nanomed. Nanotechnol. Biol. Med. 2010, 6, 698-705. [CrossRef]

31. Perez, J.M.; Asati, A.; Nath, S.; Kaittanis, C. Synthesis of biocompatible dextran-coated nanoceria with pH-dependent antioxidant properties. Small 2010, 4, 552-556. [CrossRef] [PubMed]

32. Xu, C.; Qu, X. Cerium oxide nanoparticle: A remarkably versatile rare earth nanomaterial for biological applications. NPG Asia Mater. 2014, 6, e90. [CrossRef]

33. Lin, W.; Huang, Y.W.; Zhou, X.D.; Ma, Y. Toxicity of Cerium Oxide Nanoparticles in Human Lung Cancer Cells. Int. J. Toxicol. 2006, 25, 451-457. [CrossRef] [PubMed]

34. Esmail, N.; Hoda, K.S.; Reza, N. Evaluation of anticancer effects of cerium oxide nanoparticles on mouse fibrosarcoma cell line. J. Cell. Physiol. 2018, 234, 4987-4996.

35. Jana, S.K.; Banerjee, P.; Das, S.; Seal, S.; Chaudhury, K. Redox-active nanoceria depolarize mitochondrial membrane of human colon cancer cells. J. Nanopart. Res. 2014, 16, 1-9. [CrossRef]

36. Yang, G.L.; Ko, H.H.; Hsu, Y.W. Growth behavior of nanosized ceria powders prepared by coprecipitation routes. Ceram. Int. 2013, 39, 6805-6811. [CrossRef]

37. Liu, J.; Wang, J.; Li, Y.; Jia, P.; Lu, F.; Chen, K. Hydrothermal synthesis of monodisperse $\alpha-\mathrm{Fe}_{2} \mathrm{O}_{3}$ nanocubes. Mater. Res. Innov. 2015, 19, S5-371-S5-375. [CrossRef]

38. Pinjari, D.V.; Pandit, A.B. Room temperature synthesis of crystalline $\mathrm{CeO}_{2}$ nanopowder: Advantage of sonochemical method over conventional method. Ultrason. Sonochem. 2011, 18, 1118-1123. [CrossRef]

39. Zhang, J.; Ju, X.; Wu, Z.Y.; Liu, T.; Hu, T.D.; Xie, Y.N.; Zhang, Z.L. Structural Characteristics of Cerium Oxide Nanocrystals Prepared by the Microemulsion Method. Chem. Mater. 2001, 1, 73-78. [CrossRef]

40. Tambat, S.; Umale, S.; Sontakke, S. Photocatalytic degradation of Milling Yellow dye using sol-gel synthesized $\mathrm{CeO}_{2}$. Mater. Res. Bull. 2016, 76, 466-472. [CrossRef]

41. Zhang, B.; Huyan, Y.; Wang, J. Synthesis of $\mathrm{CeO}_{2}$ nanoparticles with different morphologies and their properties as peroxidase mimic. J. Am. Ceram. Soc. 2018, 102, 2218-2227. 
42. Hayat, A.; Andreescu, S. Nanoceria particles as catalytic amplifiers for alkaline phosphatase assays. Anal. Chem. 2013, 85, 10028-10032. [CrossRef]

43. Xiao, X.; Luan, Q.; Yao, X. Single-crystal $\mathrm{CeO}_{2}$ nanocubes used for the direct electron transfer and electrocatalysis of horseradish peroxidase. Biosens. Bioelectron. 2009, 24, 2447-2451. [CrossRef]

44. Li, X.; Zhang, Z.; Tao, L. A chemiluminescence microarray based on catalysis by $\mathrm{CeO}(2)$ nanoparticles and its application to determine the rate of removal of hydrogen peroxide by human erythrocytes. Appl. Biochem. Biotechnol. 2013, $171,63-71$. [CrossRef]

45. Korsvik, C.; Patil, S.; Seal, S.; Self, W.T. Superoxide dismutase mimetic properties exhibited by vacancy engineered ceria nanoparticles. Chem. Commun. 2007, 14, 1056-1058. [CrossRef]

46. Wei, X.; Li, X.; Feng, Y. Morphology- and pH-dependent peroxidase mimetic activity of nanoceria. RSC Adv. 2018, 8, 11764-11770. [CrossRef]

47. Tian, Z.; Li, J.; Zhang, Z. Highly sensitive and robust peroxidase-like activity of porous nanorods of ceria and their application for breast cancer detection. Biomaterials 2015, 59, 116-124. [CrossRef] [PubMed]

48. Gao, L.; Zhuang, J.; Nie, L.; Zhang, J.; Zhang, Y.; Gu, N.; Wang, T.; Feng, J.; Yang, D.; Perrett, S.; et al. Intrinsic peroxidase-like activity of ferromagnetic nanoparticles. Nat. Nanotechnol. 2007, 2, 577-583. [CrossRef] [PubMed]

49. Jiao, X.; Song, H.; Zhao, H. Well-redispersed ceria nanoparticles: Promising peroxidase mimetics for $\mathrm{H}_{2} \mathrm{O}_{2}$ and glucose detection. Anal. Methods 2012, 4, 3261. [CrossRef]

50. Attar, F.; Shahpar, M.G.; Rasti, B. Nanozymes with intrinsic peroxidase-like activities. J. Mol. Liq. 2019, 278, 130-144. [CrossRef]

51. Rzigalinski, B.A.; Carfagna, C.S.; Ehrich, M. Cerium oxide nanoparticles in neuroprotection and considerations for efficacy and safety. Wiley Interdiscip. Rev. Nanomed. Nanobiotechnol. 2017, 9, e1444. [CrossRef] [PubMed]

52. Celardo, I.; Pedersen, J.Z.; Traversa, E.; Ghibelli, L. Pharmacological potential of cerium oxide nanoparticles. Nanoscale 2011, 3, 1411-1420. [CrossRef]

53. Li, C.; Yue, L.; Wang, J. Synthesis of $\mathrm{CeO}_{2}$ hollow microspheres with oxidase-like activity and their application in the catalytic degradation of p-nitrophenol. Environ. Technol. 2019, 42, 134-140. [CrossRef]

54. Peng, Y.; Chen, X.; Yi, G.; Gao, Z. Mechanism of the oxidation of organic dyes in the presence of nanoceria. Chem. Commun. 2011, 47, 2916-2918. [CrossRef]

55. Di Monte, R.; Kašpar, J. On the Role of Oxygen Storage in Three-Way Catalysis. Top. Catal. 2004, 28, 47-57. [CrossRef]

56. Franklin, S.J. Lanthanide-mediated DNA hydrolysis. Curr. Opin. Chem. Biol. 2001, 5, 201-208. [CrossRef]

57. Chin, J. Artificial dinuclear phosphoesterases. Curr. Opin. Chem. Biol. 1997, 1, 514-521. [CrossRef]

58. Chong, Y.; Liu, Q.; Ge, C. Advances in oxidase-mimicking nanozymes: Classification, activity regulation and biomedical applications. Nano Today 2021, 37, 101076. [CrossRef]

59. Tinoco, M.; Fernandez-Garcia, S.; Villa, A. Selective oxidation of glycerol on morphology controlled ceria nanomaterials. Catal. Sci. Technol. 2019, 9, 2328-2334. [CrossRef]

60. Udayabhaskar, R.; Sahlevani, S.F.; Prabhakaran, T. Modulation of optical and photocatalytic properties by morphology and microstrain in hierarchical ceria nanostructures. Solar Energy Mater. Sol. Cells 2019, 195, 106-113. [CrossRef]

61. Huang, Y.; Ren, J.; Qu, X. Nanozymes: Classification, Catalytic Mechanisms, Activity Regulation, and Applications. Chem. Rev. 2019, 119, 4357-4412. [CrossRef]

62. Chen, A.; Yu, X.; Zhou, Y.; Miao, S.; Li, Y.; Kuld, S.; Shen, W. Structure of the catalytically active copper-ceria interfacial perimeter. Nat. Catal. 2019, 2, 334-341. [CrossRef]

63. Akbayrak, S.; Tonbul, Y.; Zkar, S. Ceria Supported Rhodium Nanoparticles: Superb Catalytic Activity in Hydrogen Generation from the Hydrolysis of Ammonia Borane. Appl. Catal. B Environ. 2016, 198, 162-170. [CrossRef]

64. Mullen, G.M.; Evans, E.J.; Siegert, B. The interplay between ceria particle size, reducibility, and ethanol oxidation activity of ceria-supported gold catalysts. React. Chem. Eng. 2018, 3, 75-85. [CrossRef]

65. Liu, B.; Liu, J. Surface modification of nanozymes. Nano Res. 2017, 10, 1125-1148. [CrossRef]

66. Liu, B.; Huang, Z.; Liu, J. Boosting the oxidase mimicking activity of nanoceria by fluoride capping: Rivaling protein enzymes and ultrasensitive F-detection. Nanoscale 2016, 8, 13562-13567. [CrossRef] [PubMed]

67. Zhao, Y.; Wang, Y.; Mathur, A. Fluoride-capped nanoceria as highly efficient oxidase-mimicking nanozyme: Inhibiting product adsorption and increasing oxygen vacancy. Nanoscale 2019, 11, 17841-17850. [CrossRef]

68. Pautler, R.; Kelly, E.Y.; Huang, P.-J.J.; Cao, J.; Liu, B.; Liu, J. Attaching DNA to Nanoceria: Regulating Oxidase Activity and Fluorescence Quenching. ACS Appl. Mater. Interfaces 2013, 5, 6820-6825. [CrossRef] [PubMed]

69. Tian, Z.; Liu, H.; Guo, Z. A pH-Responsive Polymer-CeO(2) Hybrid to Catalytically Generate Oxidative Stress for Tumor Therapy. Small 2020, 16, e2004654. [CrossRef] [PubMed]

70. Naqvi, S.T.R.; Shirinfar, B.; Majeed, S.; Najam-ul-Haq, M.; Hussain, D.; Iqbal, T.; Ahmed, N. Synthesis, design and sensing applications of nanostructured ceria-based materials. Analyst 2018, 143, 5610-5628. [CrossRef]

71. Niu, B.; Xiao, K.; Huang, X.; Zhang, Z.; Kong, X.-Y.; Wang, Z.; Wen, L.; Jiang, L. High-Sensitivity Detection of Iron(III) by Dopamine-Modified Funnel-Shaped Nanochannels. ACS Appl. Mater. Interfaces 2018, 10, 22632-22639. [CrossRef] [PubMed]

72. Qin, J.; Feng, Y.; Cheng, D. Construction of a Mesoporous Ceria Hollow Sphere/Enzyme Nanoreactor for Enhanced Cascade Catalytic Antibacterial Therapy. ACS Appl. Mater. Interfaces 2021, 13, 40302-40314. [CrossRef] 
73. Damle, M.A.; Jakhade, A.P.; Chikate, R.C. Modulating Pro- A nd Antioxidant Activities of Nanoengineered Cerium Dioxide Nanoparticles against Escherichia coli. ACS Omega 2019, 4, 3761-3771. [CrossRef]

74. Xu, C.; Lin, Y.; Wang, J.; Wu, L.; Wei, W.; Ren, J.; Qu, X. Nanoceria-triggered synergetic drug release based on CeO(2)-capped mesoporous silica host-guest interactions and switchable enzymatic activity and cellular effects of $\mathrm{CeO}(2)$. Adv. Healthc. Mater. 2013, 2, 1591-1599. [CrossRef] [PubMed]

75. Li, M.; Shi, P.; Xu, C.; Ren, J.; Qu, X. Cerium oxide caged metal chelator: Anti-aggregation and anti-oxidation integrated $\mathrm{H}_{2} \mathrm{O}_{2}$-responsive controlled drug release for potential Alzheimer's disease treatment. Chem. Sci. 2013, 4, 2536-2542. [CrossRef] 